\title{
Nötron Buharlaşma Tepkimelerinde Algıç Benzetimi ve Olay Üretimi için Veri Güdümlü GEANT4 Sinıfları
}

\author{
Oktay Doğangün ${ }^{\mathrm{a}, \mathrm{d}, 1^{*}}$, M. Nizamettin Erduran ${ }^{\mathrm{b}, \mathrm{d}, 2}$, Ferhat Özok $^{\mathrm{c}, 3}$ \\ a İstanbul Sabahattin Zaim Üniversitesi, Mühendislik ve Doğa Bilimleri Fakültesi, Elektrik-Elektronik Mühendisliği Bölümü, İstanbul, Türkiye \\ b İstanbul Sabahattin Zaim Üniversitesi, Mühendislik ve Doğa Bilimleri Fakültesi, Bilgisayar Mühendisliği Bölümü, İstanbul, Türkiye \\ c Mimar Sinan Güzel Sanatlar Üniversitesi, Fen-Edebiyat Fakültesi, Fizik Bölümü, İstanbul, Türkiye \\ d İstanbul Sabahattin Zaim Üniversitesi, Nükleer Algllayıcılar ve Robotik Uygulama ve Araştırma Merkezi, Istanbul, Türkiye
}

İstanbul Sabahattin Zaim Üniversitesi Fen Bilimleri Enstitüsü Dergisi (2021) 3 (1): 15-20

https://doi.org/10.47769/izufbed.861775

(iD) $O R C I D{ }^{1} 0000-0002-1255-2211 ;{ }^{2}$ 0000-0003-0852-9753; ${ }^{3}$ 0000-0001-9630-7362

\begin{tabular}{l}
\hline YAYIN BİLGİSI \\
\hline Yayın geçmişi: \\
Gönderilen tarih: 15 Ocak 2021 \\
Kabul tarihi:28 Ocak 2021 \\
\end{tabular}

Anahtar kelimeler:

GEANT4

Algıç Benzetimleri

Olay Üretimi

Monte Carlo Benzetimleri

$\mathrm{C} / \mathrm{C}++$ Kütüphaneleri

\begin{abstract}
ÖZET
Yüksek Enerji Fiziği alanında temel olarak algıç benzetimleri oluşturmak için kullanılan açık kaynak kodlu bir $\mathrm{C} / \mathrm{C}++$ kütüphanesi olan GEANT4 belli bir fiziksel sürecin olay üretimini yapabilme imkanı sağlamaktadır. Bu bildiride, daha düşük enerjilerin söz konusu olduğu Çekirdek Fiziğinde Nötron Buharlaşma tepkimeleri olarak bilinen nadir bir süreç için veri güdümlü yeni GEANT4 sınıfları yazılmıştır. $\mathrm{C} / \mathrm{C}++$ dilinde yazılmış bu sınıflar, söz konusu kütüphanede hal-i hazırda tanımlı olan süreç sınıfindan türetilmiş olup, etkileşim tesir kesitleri ise ENDF/B-VII (Evaluated Nuclear Data Library) adlı deneysel çekirdek etkileşimlerinin veri tabanı dahil edilerek hesaplanmıştır. Belirli birkaç örnek için üretilen sonuçlar, NEDA (NEutron Detector Array) deneylerine özel yazılmış ve sınanmış olan benzetimlerle karşılaştırmalı olarak sunulmuştur
\end{abstract}

\section{Data-Driven GEANT4 Classes for Detector Simulations and Event Generation in Neutron Evaporation Reactions}

\begin{tabular}{l}
\hline ARTICLE INFO \\
\hline Article history: \\
Received: 15 January 2021 \\
Accepted:28 January 2021 \\
\hline Key words: \\
GEANT4 \\
Detector Simulations \\
Monte Carlo Simulations \\
Event Generation \\
C/C++ Libraries \\
\end{tabular}

\section{Giriş}

Erişimin ve yeniden dağıtımın "açık" hale getirildiği kaynak

\begin{abstract}
GEANT4, as an open-source C/C++ library mainly used to code detector simulations in HighEnergy Physics, also provides the possiblity to generate pseudo events of a physical process. In this work, new data-driven GEANT4 classes are implemented for a rare process known as Neutron Evaporation reactions in Nuclear Physics where lower energies are relevant. These classes implemented in $\mathrm{C} / \mathrm{C}++$ language are derived from an existing class in the library in subject, and the cross-section of the reactions are calculated by including a database of nuclear interactions called ENDF/B-VII (Evaluated Nuclear Data Library). Results produced for some specific cases are presented by comparing specialized simulations written and tested for NEDA (NEutron Detector Array) experiments.
\end{abstract}

kodlar içeren "açık kaynak kodlu yazılımlar", Bilgisayar Bilimi ve Yazılım alanlarında, hatta artık günümüzde son kullanıcının günlük yaşamında yaygın olduğu kadar, yazılımla 
iç içe olan Fizik alanında da yaygınlaşmış durumdadır. Özellikle Nükleer Fizik ve Yüksek Enerji Fiziği bilim dallarında hem kullanılan yazılımların hem de o alanlarda çalışan araştırmacılar tarafindan yazılan kodların açık kaynak olması, en küçük yerel projelerden en büyük uluslararası laboratuvar işbirliklerine dek geniş bir yelpazede henüz kavramın ilk yıllarından beri merkeze oturmuş bulunuyor [Swain, 1997]. Nitekim, bu bilim dallarındaki çalışmaların bir uzantısı olarak da bu çalışma, açık kaynak kodlu kütüphaneler üzerinden yürütülmüştür.

$\mathrm{Bu}$ çalışmada sunulan "veri güdümlü" sınıfın ait olduğu kütüphane, yüksek enerji fiziğinde algıç benzetimleri için kullanılan GEANT4 [Agostinelli et al., 2002] olup karşılaştırmaları yaptığımız kütüphane ise, yine yüksek enerji fiziğinde fizik analizleri için kullanılan ROOT [Brun et al., 2000] kütüphanesidir.

Sunulan bu çalışma, TÜBİTAK-117F114 numaralı proje1 için nükleer fizik benzetimlerine ihtiyaç doğmasının bir sonucu olarak açık kaynak kodlu yazılan bir $\mathrm{C} / \mathrm{C}++$ sınıfı üzerinedir. Yazılan bu sınıf, söz konusu projede incelemek için gerek duyulan fiziksel olayların benzetim verisinin üretiminde rol oynayarak, düşük enerjili iyon çarpışmalarını daha ayrıntılı incelememize yardımcı olmuştur. Nitekim, proje kapsamında araştırılan tepkimeler için "olay üretimi" ihtiyacı, hâli hazırda var olan GEANT4 sınıfları içerisinde tam olarak karşılanmamakta, onun yerine yardımcı benzetim yazılımları kullanılmaktadır [Di Nitto et al., 2012]. Olayların bir yazılımda üretilip algıç etkileşiminin başka bir yazılımda yapılması çözümü her ne kadar geçerli ve yaygın bir yöntem olsa da, tek bir yazılımın içinde hem olayların üretilmesi hem de algıç tepkisinin benzetimlenmesi başarım olarak daha iyi ve pratik açıdan birçok avantaja sahip olup bu çalışmanın bir başka motivasyon kaynağını oluşturmuştur.

Söz konusu TÜBİTAK projesi, ağır iyonların etkileşimlerinin anlaışmasında rol oynayan nötronları algılamak üzerine uzmanlaşmış NEDA (Neutron Detector Array) adında bir algıç dizininin yapımı, kurulumu, sınanması ve fiziği için gerçekleştirilmiş bir araştırmadır [Jarowski, 2019] [Hüyük, 2016]. Projede NEDA dizinde yapılacak deneylerin tasarlanması ve edinilen verilerin incelenmesi için ihtiyaç duyulan "fizik benzetimleri" ise iki çekirdeğin çarpışması ve ardından oluşan kararsız ağır çekirdeğin belli sayıda nötron kaybetmesi sürecini simüle etmek için yazılan yazılımlardır.

NEDA dizini, 257 algıçtan oluşan tam dizi ve 37 algıçtan oluşan prova dizisi olarak tasarlanmıştır (Şekil 1). Burada "algıç" (dedektör) denen bileşen, sintilatör adlı bir tür malzemeden yapılmış bir altıgen prizma olup nötronlar geldiğinde 1şıma yaparak nihayetinde elektronik donanımda bir sinyal üretmektedir. Projede gerçekleştirilen benzetimlerde parçacıkların üretilmesi ve ortaya çıkan parçacıkların tasarlanan algıçlarla olan etkileşimi çeşitli açık kaynak kodlu araçlar üzerinden yapılmıştır. Proje tüm bu aşamaları kapsasa da yalnızca nötronların üretilmesiyle ilgili benzetimler bu bildirinin konusu olacaktır.

Algıçlara gelen nötronların en başta üretildiği nükleer tepkimeleri inceleyebilmek ve öngörüleri hesaplayabilmek için fizik benzetimleri yapma ihtiyacı, birtakım açık kaynak kodlu araçlar kullanılarak karşılanmaktadır. Ancak söz konusu araçların yetmediği durumlarda ihtiyaca yanıt verecek eklemeler yapılması gerekmiştir. Kullanılan araçların açık kaynak kodlu olmaları, bu eklemeleri olanaklı hale getirmiş olup bu bildiride söz konusu eklemelerden biri sunulmaktadır.

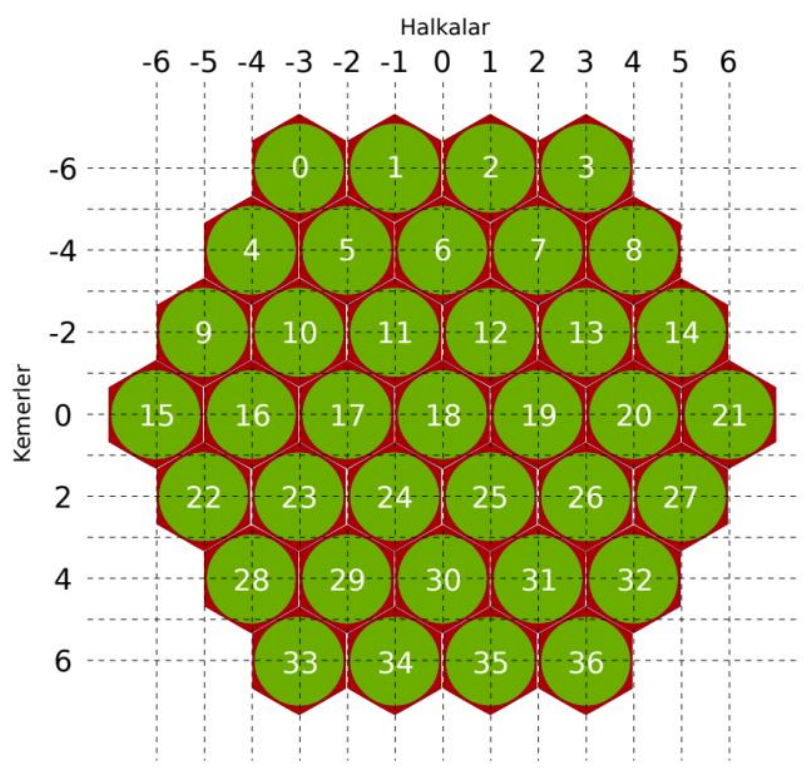

Şekil 1. Otuzyedi algıçlık prova NEDA dizisinin önden görünümü. Her algıç 5 inç çapında ve $20 \mathrm{~cm}$ derinlikte altıgen prizmalardan oluşuyor.

Kullandığımız araçlardan biri olan GEANT4 (GEometry ANd Tracking) kütüphanesi, yüksek enerji fiziğindeki algıç benzetimlerini yapmak amaciyla CERN (Avrupa Nükleer Araştırma Merkezi) tarafindan oluşturulmuş açık kaynak kodlu bir $\mathrm{C} / \mathrm{C}++$ sınıfları hiyerarşisidir [Agostinelli et al., 2002]. Çok katmanlı ve hiyerarşik yapıdaki bu kütüphane sayesinde, algıçların geometrisini, parçacıkların izlerini, malzemelerin tepkisini yöneterek Monte Carlo yöntemleriyle fiziksel süreçleri adım adım hesaplayabilen yazılımlar yazılabilmektedir.

Bildirimizde yazılan $\mathrm{C}++$ sınıflarının amacı ağır çekirdek iyonlarının hedefe çarpıştırılması sonucunda oluşacak tepkimeleri deneye uygun bir oranda üretebilmektir. Deneysel veriler üzerinden bir benzetim yapılması nedeniyle yazdığımız sınıf "veri güdümlü" olarak adlandırılır. Literatürde "olay üretimi" olarak bilinen bu benzetim aşaması, Monte Carlo adıyla bilinen bir istatistiksel yöntemle gerçekleştirilir [Metropolis, 1949]. Bu yönteme göre bir tepkimenin/sürecin gerçekleşmesi olası durumların ağırlıklarına göre rastgele seçilmektedir. Örneğin, durgun Nikel-58 hedefine belli bir enerjide gelen bir Demir-56 iyonu, hedefin atom yoğunluğu oranında rastgele bir atomuyla etkileşiyor olsun. Demir-56 iyonu yok olup Xenon-114 kararsız çekirdeğini oluşturabileceği gibi, yalnızca sekip başka enerji ve doğrultuda devam edebilir. Ardından Xenon- 
114, bazen 3 bazen 2 nötronunu buharlaştırır (Şekil 2 ve 4).

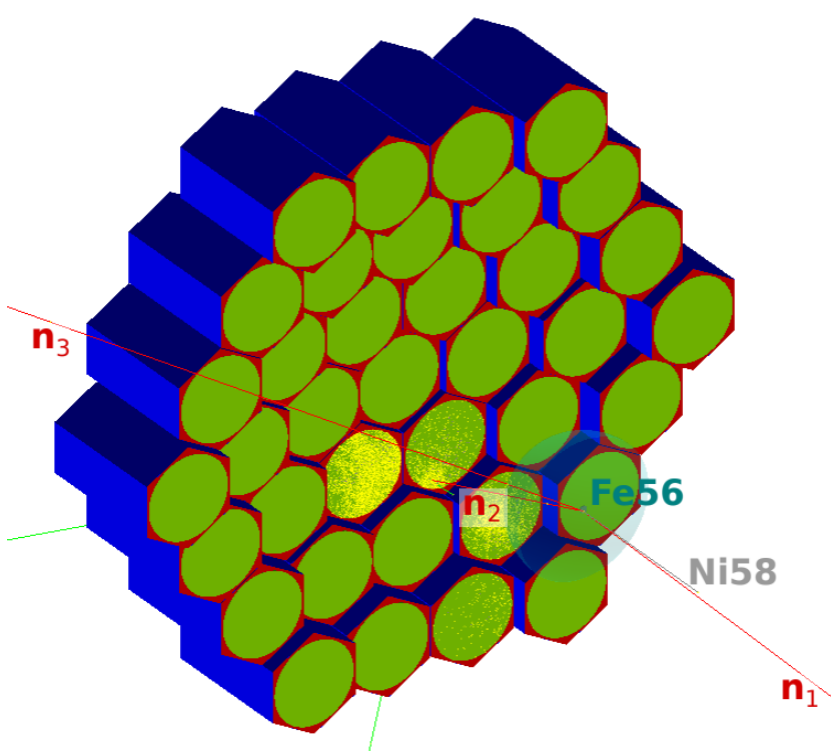

Şekil 2. Profilden görüntülenen prova NEDA dizisine gelen Nikel58 (gri) çekirdeğinin Demir-56 (turkuaz) hedefine çarpıp 3 nötron (kırmızı) oluşturduğu ve etkileştiği algıçlarda ışıma (sarı) yaptığı örnek bir olay.

$\mathrm{Bu}$ olası son durumlar arasından hangisinin gerçekleşeceği, bu durumların tesir kesiti adı verilen enerjiye de bağlı olan olasılık dağılımlarına göre rastgele bir çıktı verecek şekilde belirlenmektedir. GEANT4 temelde süreçteki tüm parçacıklar için adım adım bunu hesaplamaya yarayan bir araçtır, ancak bu araç daha çok yüksek enerji fiziği odaklı olduğu için daha düşük enerjilerdeki düşük tesir kesitli ağır çekirdek deneylerinin tüm etkileşim uzayını henüz kapsayabilmiş değildir. Bu kapsamın artırılması amacıyla ENDF/B-VII veri kütüphanelerinden [Chadwick, 2006] elde edilen tesir kesitleri nötronların algıçta yarattığı belli tepkimeler için derlenmiş ve kullanılmıştır.

Bir sonraki bölümde Nötron Buharlaşması için yazılan GEANT4 tabanlı C/C++ sınıfının üst yapısı ve GEANT4 içindeki işlevi sunulup üçüncü bölümde kimi örnekler üzerinden daha önce ROOT tabanlı olarak yazılmış benzetimlerle karşılaştırılacaktır. Dördüncü bölümde sonuçlar tartışılmıştır.

\section{2. Önerilen NeutronEvaporationProcess Sinıfının Yapısı ve Yeri}

Karmaşık olayların benzetimini yapmak, doğal olarak karmaşık yapılar gerektirebilir. Fizik alanında benzetimler yapmak için, özellikle deneysel parçacık fiziği ve nükleer fizik özelinde, kuramdan modele ve modelden deneysel donanıma kadar birçok aşama söz konusu olmaktadır.

Bu yüzden GEANT4 paketinde tanımlı kütüphaneler de Yüksek Enerji Fiziğinin birçok alt dalında çalışabilecek tepkimeyi, fiziksel değişkenleri ve geometriyi ele almak üzere inşa edildiğinden çok katmanlı ve iç içe bir hiyerarşiye sahiptir: bir parçacığın üretilmesi, adım adım ilerletilmesi, parçacığın bulunduğu ortamın malzeme nitelikleri ve geometrisi, parçacığın her adımda bulunduğu ortamla hangi etkileşimleri yapabileceği, söz konusu etkileşimin olma sıklığı, ardından tekrar etkileşimden çıkan parçacıklar için aynı aşamaların gerçekleşmesi gibi katmanlar bulunmaktatır. $\mathrm{Bu}$ bildiride kullanılan sınıfları irdeleyelim (Şekil 3). En tepede G4ParticleChange sınıfı, süreç içindeki her parçacığın her adımda hangi model üzerinden değiştiğini tutmak için tanımlanmıştır. $\mathrm{Bu}$ sınıfın altında G4Track sınıfı, G4ParticleDefinition sınıfından bir parçacığın adımlarını (G4Step) tutar. Söz konusu bu parçacık sınıfı da, özünde G4VProcess listesi olan bir Süreç Yöneticisi (G4ProcessManager) sınıfına sahiptir. Bu süreç sınıfları da bir yandan fiziksel modelleri (G4HadronicInteractions) tutarken bir yandan da tepkimenin hangi olasılıkla gerçekleşeceğini bildiren tesir kesitlerini (G4HadronCrossSections) içermektedir.

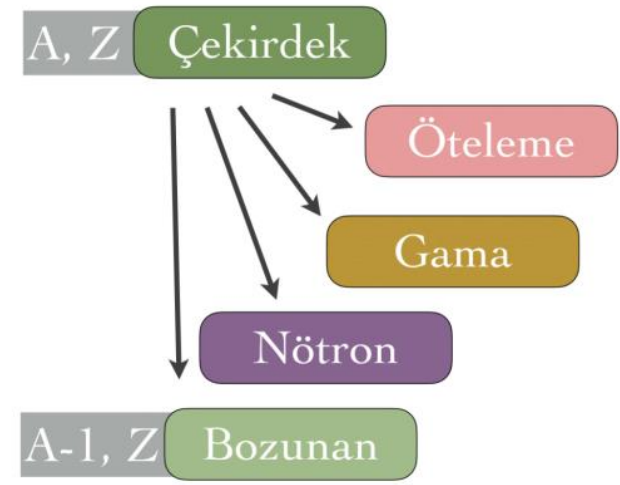

Şekil 3. Çekirdek-çekirdek etkileşiminde ortaya çıkan son durum parçacıkları ve alt süreçler. Her nötron buharlaşmasında çekirdeğin kütle numarası 1 azalıp yeni bir kalıntı (bozunan) çekirdek ortaya çıkar.

Çalışmanın ürünü olarak NeutronEvaporationProcess adını verdiğimiz GEANT4 sınıfı, G4VProcess sınıfından türetilerek ilgili parçacıkların Süreç Yöneticisi sınıflarına eklenmiştir. Bu nedenle bu sınıf, yalnızca ilgili bir parçacı ğın ilgili hedefle etkileşmesi söz konusu olduğu sürece yürütülecektir. Sınıftaki rutinlerden en önemlisi, ApplyYourself() adlı işlevdir. Bu işlev, gelen parçacık (G4DynamicParticle) bilgisiyle hedef malzeme (G4Material) bilgisini alır ve son durum parçacıklarının dinamik olarak (enerji ve momentum bilgisiyle) içerildiği G4ParticleChange sınıfının adresini döndürür. Böylece GEANT4 benzetimi, bir sonraki adımda hangi parçacığın hangi enerji ve doğrultuda olacağını, hangi parçacıkların ise yok olduğunu belirlemiş olur.

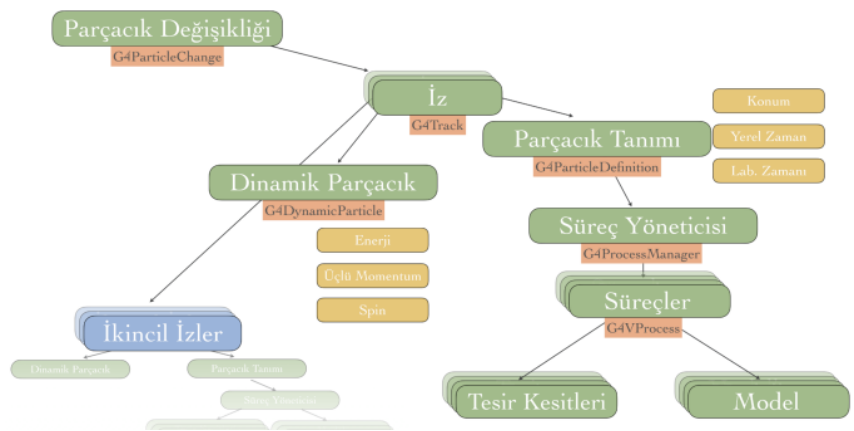

\section{Olay Üretimi Örnekleri ve Kontrol Benzetimiyle Karşılaştırılması}

“Olay üretimi” kavramı, analiz edilmek istenen olayların ilgilenilen fiziksel süreçlere uygun genlikte ve uygun 
dağılımda, genellikle de Monte Carlo yöntemi kullanılarak oluşturulmasına verilen addır. Örneğin bir çarpışma sonucunda ortaya hangi parçacıkların hangi olasılıkta oluşacağı, hangi doğrultuda ve enerjilerde tepkimeden çıkacağı belirlenmelidir. Bazı tepkimeler, temel ilkelerden ve kuramlardan yola çıkarak hesaplanabilirken bazıları ise deneysel olarak bilinmektedir. Bu çalışmadaki örneklerde tepkimelerde hangi parçacıkların ne olasılıkta çıkacağı bilgisi deneysel olarak yazılıma aktarılmış olduğu için yazılan sınıf “veri güdümlü” olarak adlandırılır.

Bu çalışmada üretilecek olaylar iyon çarpışmaları sonucunda oluşan kararsız çekirdekler, ardından da o çekirdeklerin bozunarak belli sayıda nötron ve bir kalıntı çekirdek çıkarması olarak belirlenmiştir. Bu belirlemenin nedeni, NEDA algıç dizininde yapılacak deneylerin bu tür tepkimeler içermesidir.

Tepkimeler de kendi içinde nötron çokluğuna (kaç nötronun buharlaştığına) göre "kanal" adı verilen kategorilere ayrılmıştır. NEDA dizini, kaç nötron olduğunu ve hangi algıçlarda sinyal bıraktığını saptayabilecek donanımdadır. Bu saptamalardan yola çıkarak, nötronların tepkimeden çıkış doğrultuları, bıraktıkları sinyalin niteliği sayesinde de enerji dağılımları bulunabilir.

Üretilen sonuçlar, proje kapsamında daha önceden yazılmış olan olay üretimi benzetimleri ile karşılaştırılmıştır. Bu kontrol benzetimleri, yine CERN tarafından geliştirilmiş olan ROOT C/C++ yorumlayıcısı [Brun et al., 2000] tabanlı ve sözü edilen TÜBİTAK projesine özgü olarak yazdığımız bir yazılımla üretilmiştir. Bu yazılımın başarımı proje sürecinde doğrulanmış olduğundan dolayı, karşılaştırmada "kontrol benzetimi" olarak seçilmiştir.

Karşılaştırmayı yapabilmek için GEANT4 sınıflarından G4GeneralParticleSource adlı parçacık kaynağı sınıfından yararlanılarak $+Z$ yönünde belli bir hedefe doğru ağır iyonlar üretilmiş ve hedefteki malzemenin çekirdekleriyle etkileşmesi sağlanmıştır. $\mathrm{Bu}$ etkileşimde ilgilendiğimiz süreç, çekirdeklerin birleşmesi ve ardından nötron salarak taban durumuna geçmeleridir. $\mathrm{Bu}$ türden düşük enerjili ağır çekirdek-çekirdek etkileşimlerinin tesir kesitleri ve ayrıca sonucunda oluşan parçacıkların neler olduğu, momentumları ve enerjileri henüz GEANT4 olanakları kullanılarak yüksek güvenilirlikle sağlanamamaktadır. $\mathrm{Bu}$ nedenle bu birleşmebuharlaşma tepkimelerinden çıkan son durum parçacıklarının dinamik nicelikleri, yukarıda da belirtildiği gibi NeutronEvaporationProcess adını verdiğimiz yeni bir süreç sınıfı yazılarak belirlenmiştir. Tesir kesitleri ise aşağıda ayrıntılı anlatıldığı üzere deneysel verilerden elde edilmiştir (Tablo 1).

Kanal kısaltmaları; nötron çokluğu, ardından demet iyonu ve hedef çekirdeği kısaltmalarıyla adlandırılmıştır. Örneğin Nikel-58 demetinin Demir-56 hedefine çarpıp 3 nötron oluşturduğu kanal $3 \mathrm{n}-{ }^{58} \mathrm{Ni}+{ }^{56} \mathrm{Fe}$ olarak kısaltılmıştır.

${ }^{2 n-}{ }^{58} \mathrm{Ni}+{ }^{56}$ Fe ve $3 n-{ }^{58} \mathrm{Ni}+{ }^{56}$ Fe kanalları. Bu kanallarda Demir-56 izotopundan oluşan hedefe Nikel-58 izotopu 220 $\mathrm{MeV}$ enerjide $+\mathrm{Z}$ yönünde gönderilmektedir. Bu iki çekirdek birleşme yaparak Zenon-114 izotopu oluşturup ya 2 ya da 3 nötronunu buharlaştırır. Görece kütle merkezi enerjisi yüksek olduğu için $+Z$ yönünde iteklenmiş (boosted) bir yön dağılımı oluşturur. GEANT4 tabanlı NeutronEvaporationProcess sınıfı ile ROOT tabanlı kontrol benzetimini nötron çokluğu açısından karşılaştırdığımızda yüksek mertebede örtüştüğü görülmektedir (Şekil 5).

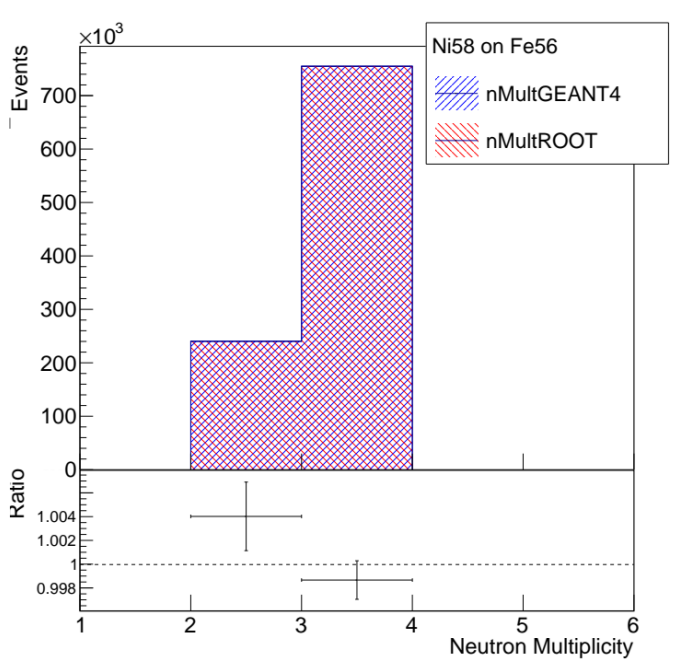

Şekil 5 .

Demir-56 üzerine $220 \mathrm{MeV}$ enerjili Nikel-58 çekirdeği gönderilmesi sonucunda ortaya çıkan nötronların çokluğunun ROOT tabanl kontrol benzetimi (kırmızı) ile bu çalışmada önerilen GEANT4 tabanlı benzetimin (mavi) karşılaştırması.

- $n-{ }^{12} \mathrm{C}+{ }^{133} \mathrm{Cs}$, $2 \mathrm{n}-{ }^{-12} \mathrm{C}+{ }^{133} \mathrm{Cs}$ ve $3 \mathrm{n}-{ }^{12} \mathrm{C}+{ }^{133} \mathrm{Cs}$ kanalları. $\mathrm{Bu}$ kanallarda hedef çekirdek olarak Sezyum-133 izotopu bulunurken demet olarak $40 \mathrm{MeV}$ enerjide Karbon-12 izotopu $+Z$ yönünde gönderilir. Yine birleşme ve buharlaşma tepkimeleri sonucu sırasıyla 1, 2 veya 3 nötron oluşturulmuş olup yön dağılımı görece düşük enerjili bir tepkime olduğundan yaklaşık olarak eş yönlü olur. Bu kanallar düşük nötron çokluğu durumlarını analiz edebilmemize olanak tanımaktadır. GEANT4 tabanlı NeutronEvaporationProcess

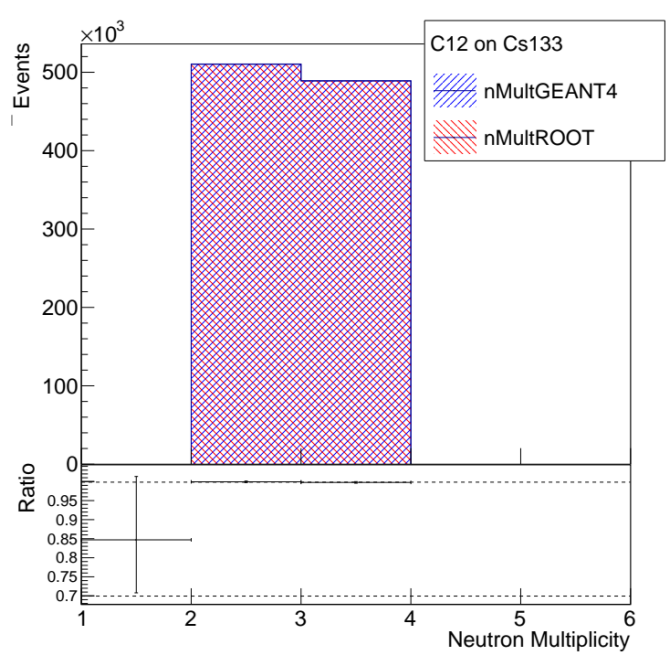

Şekil 4.

Sezyum-133 üzerine $40 \mathrm{MeV}$ enerjili Karbon-12 çekirdeği gönderilmesi sonucunda ortaya çıkan nötronların çokluğunun ROOT tabanl kontrol benzetimi (kırmızl) ile bu çalışmada önerilen GEANT4 tabanlı benzetimin (mavi) karşılaştırması. 
sınıfı ile ROOT tabanlı kontrol benzetimini nötron çokluğu açısından karşılaştırdığımızda yüksek mertebede örtüştüğü görülmektedir (Şekil 6).

${ }^{3 n}-{ }^{13} \mathrm{C}+{ }^{133} \mathrm{Cs}, 4 \mathrm{4n}-{ }^{13} \mathrm{C}+{ }^{133} \mathrm{Cs}$ ve ${ }^{5 n}-{ }^{13} \mathrm{C}+{ }^{133} \mathrm{Cs}$ kanalları. Bu kanallarda hedef çekirdek olarak Sezyum-133 izotopu bulunurken demet olarak $60 \mathrm{MeV}$ enerjide Karbon-12 izotopu $+Z$ yönünde gönderilir. Yine birleşme ve buharlaşma tepkimeleri sonucu sırasıyla 3, 4 veya 5 nötron oluşturulmuş olup yön dağılımı görece düşük enerjili bir tepkime olduğundan yaklaşık olarak eş yönlüdür. Bu kanallar, Karbon12 kanallarına oranla nötron çokluğu yüksek olması nedeniyle çalışmada incelenmektedir. GEANT4 tabanlı NeutronEvaporationProcess sınıfı ile ROOT tabanlı kontrol benzetimini nötron çokluğu açısından karşılaştırdığımızda yüksek mertebede örtüştüğü görülmektedir (Şekil 7).

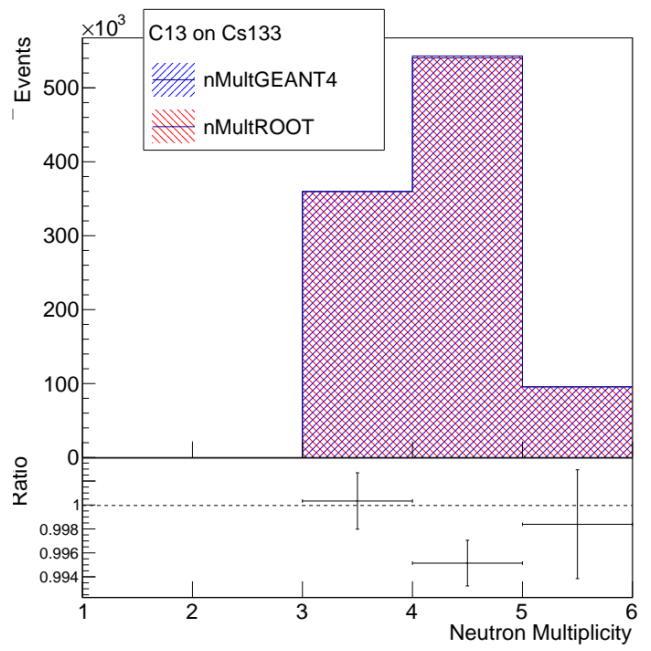

Şekil 6. Sezyum-133 üzerine $60 \mathrm{MeV}$ enerjili Karbon-13 çekirdeği gönderilmesi sonucunda ortaya çıkan nötronların çokluğunun ROOT tabanlı kontrol benzetimi (kırmızı) ile bu çalışmada önerilen GEANT4 tabanlı benzetimin (mavi) karşılaştırması.

Nötronların enerji ve momentum dağılımları, üretilen tepkimenin dinamik olarak başarımını gösterecek bir ölçüt sunacaktır. Aşağıda 2n-Ni58+Fe56 kanalında en yüksek enerjili olan nötronun ve bir sonraki nötronun enerji dağılımı gösterilmektedir (Şekil 8 ve 9).

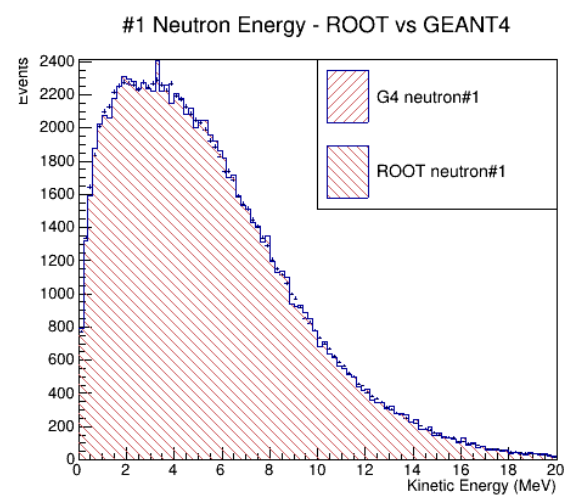

Şekil 7. Demir-56 üzerine $220 \mathrm{MeV}$ enerjili Nikel-58 çekirdeği gönderilmesi sonucunda ortaya çıkan ilk nötronların enerjilerinin ROOT tabanlı kontrol benzetimi (+ ile gösterilen) ile bu çalışmada önerilen GEANT4 tabanlı benzetimin (taralı) karşılaştırması.

Önemli diğer bir karşılaştırma da fiziksel süreçten çıkan nötronların açısal dağılımlarıdır. Açısal dağılımlar, aslında momentum doğrultularını verdiğinden momentum dağılımlarına denk bir bilgi verecektir. Örneğin Demir56 hedefine gönderilen Nikel-58 çekirdek-çekirdek etkileşiminde demetin $220 \mathrm{MeV}$ enerjili olmasından dolayı dağılımın $+Z$ yönüne doğru kaymış olması beklenmektedir. Gerçekten de ROOT tabanlı benzetimle karşılaştırıldığında aynı dağılım ortaya çıkmıştır (Şekil 9).

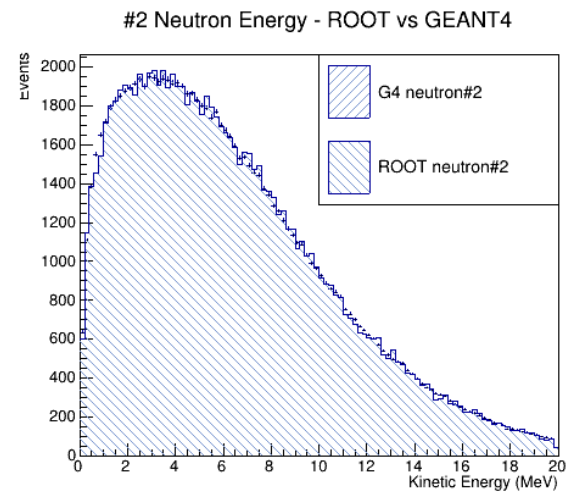

Şekil 9. Demir-56 üzerine $220 \mathrm{MeV}$ enerjili Nikel-58 çekirdeğ gönderilmesi sonucunda ortaya çıkan ikinci nötronların enerjilerinin ROOT tabanlı kontrol benzetimi (+ ile gösterilen) ile bu çalışmada önerilen GEANT4 tabanlı benzetimin (taralı) karşılaştırması.

Tablo 1. Belli enerjilerde gönderilen iyonların, kaç nötron son durumunda ne kadar olay sıklığı olacağı belirtiliyor

\begin{tabular}{|r|l|l|r|r|r|r|r|}
\hline \multirow{2}{*}{$\begin{array}{c}\text { Enerji } \\
(\mathrm{MeV})\end{array}$} & Demet & Hedef & \multicolumn{6}{|c|}{ Nötron Çokluğu } \\
\cline { 4 - 8 } & İyon & Atom & 1 & 2 & 3 & 4 & 5 \\
\hline 220 & Nikel-58 & Demir-56 & 0 & 31000 & 97000 & 0 & 0 \\
206 & Nikel-58 & Karbon-12 & 0 & 200 & 0 & 0 & 0 \\
60 & Karbon-13 & Sezyum-133 & 0 & 0 & 200 & 300 & 55 \\
40 & Karbon-12 & Sezyum-133 & 66 & 548388 & 526784 & 0 & 0 \\
\hline
\end{tabular}


$220 \mathrm{MeV}$ Enerjide Ni58+Fe56 Nötronların $\theta$ ile $\varphi$ Dağılımı (GEANT4)

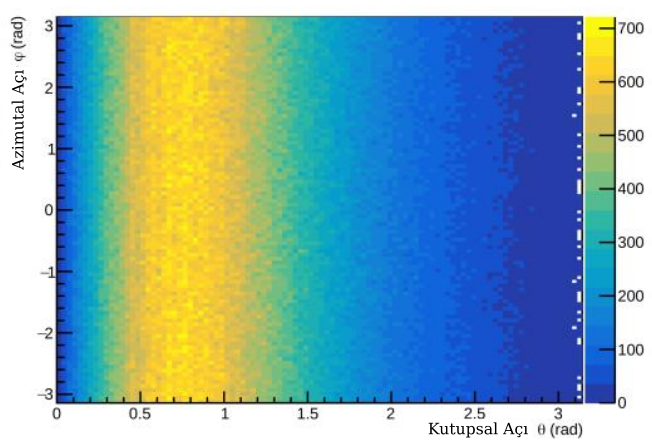

$220 \mathrm{MeV}$ Enerjide Ni58+Fe56 Nötronların $\theta$ ile $\varphi$ Dağ̆lımı (ROOT)

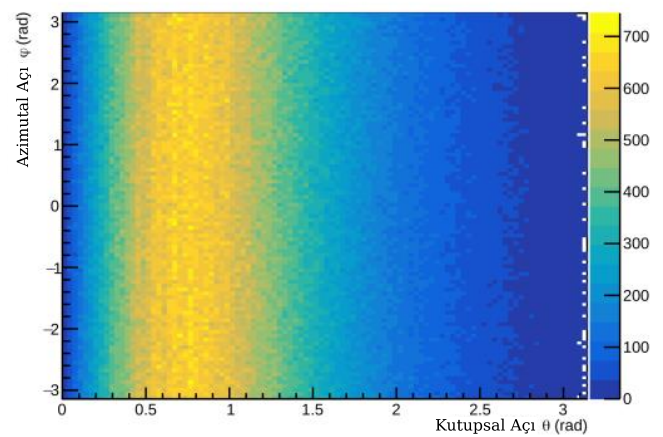

Şekil 10. 37 algıçlık prova NEDA dizisinin önden görünümü. Her algıç 5 inç çapında ve $20 \mathrm{~cm}$ derinlikte altıgen prizmalardan oluşuyor

\section{Sonuç}

Çalışmada üretilen olaylarda çeşitli tepkime kanalları için verilen nötron çokluğu karşılaştırılması, tesir kesitlerinin başka bir deyişle olayların gerçekleşme olasılık dağılımlarının başarımını göstermektedir. Nötron çokluğu, NEDA dizini açısından elde edilecek bilgilerin başında gelse de elbette nötronların dinamik olarak doğru şekilde üretilmiş olması yalnızca nötron çokluğu üzerinden anlaşılamaz. Bu nedenle enerji dağılımının ve açısal dağılımların karşılaştırılması bu çalışmada sunulan sınıfın dinamik olarak başarımını göstermektedir.

Projede NEDA dizinine özgü olarak yazılan ROOT tabanlı benzetim ile GEANT4 için önerilen. NeutronEvaporationProcess sınıfı tabanlı benzetim arasında yapılan karşılaştırmada fiziksel süreçten çıkan nötronların çokluğu 1 milyon olay sayısında bire bir örtüşmektedir: iki benzetimin nötron çoklukları farkı ortalamada \% 0.0015 çıkmıştır. Ayrıca nötronların açısal dağılımları karşılaştırıldığında da bire bir örtüştüğü görülmektedir. Nötron enerji dağılımının kontrol verileriyle örtüşmesi, üretilen tepkimenin enerji ölçütlerine uyduğunu ve açısal dağılımının örtüşmesi de tepkimenin momentum ölçütlerine uyduğunu göstermektedir.

Sonuç olarak, söz konusu iyon çarpışmaları için belirtilen fiziksel süreçlerin açık kaynak kodlu GEANT4 algıç benzetim kütüphanesinde de kullanılabilmesi için yazmış olduğumuz sınıfların başarımının yeterli ölçüde olduğu görülmüştür: hem nötron çoklukları, hem enerji dağılımları hem de açısal dağılımları örtüşmüştür.

Sonraki çalışmalarda tepkime kategorilerinin çoğaltılması, böylece GEANT4 resmi sınıflarına dahil edilmesi için gerekli hazırlıkların yapılması ve ayrıca gerçek verilerle kıyaslanması planlanmaktadir.

\section{Teşekkür}

$\mathrm{Bu}$ çalışma, TÜBİTAK ARDEB-1001 programı 117F114 numaralı proje kapsamında desteklenmiştir.
Agostinelli, S., et al. [GEANT4] (2003). GEANT4 - a simulation toolkit. Nucl. Instrum. Meth. A 506: 250303 doi:10.1016/S0168-9002(03)01368-8

Brun, R., Rademakers, F., Panacek, S. (2000). ROOT - an object oriented data analysis framework. CERN 13:11. doi:10.5170/CERN-2000-013.11

Chadwick, M.B., Obložinský, P., Herman, M., Greene, N.M., McKnight, R.D., Smith, D.L., Young, P.G., MacFarlane, R.E., Hale, G.M. , Frankle, S.C., et al. (2006). ENDF/B-VII.0: Next Generation Evaluated Nuclear Data Library for Nuclear Science and Technology. Nucl. Data Sheets 107: 2931-3060 doi:10.1016/j.nds.2006.11.001

Di Nitto, A., et al. (2013). Monte Carlo Simulations of Fusion-Evaporation Reactions for a 2pi Configuration of the NEDA Array. LNL Annual Report 2012: 82.

Hüyük, T., Di Nitto, A., Jaworski, G., Gadea, A., Javier Valiente-Dobón, J., Nyberg, J., Palacz, M., Söderström, P. A., Jose Aliaga-Varea, R., de Angelis, G., et al. (2016). Conceptual design of the early implementation of the NEutron Detector Array (NEDA) with AGATA. Eur. Phys. J. A 52 (3): 55 doi:10.1140/epja/i2016-16055-8

Jaworski, G., Goasduff, A., Egea Canet, F.J., Modamio, V., Hüyük, T., Triossi, A., Jastrzb, M., Söderström, P. A., Carturan, S. M., Di Nitto A., et al. (2019). The New Neutron Multiplicity Filter NEDA and Its First Physics Campaign with AGATA. Acta Phys. Polon. B 50 (3): 585 doi:10.5506/APhysPolB.50.585

Metropolis, N.; Ulam, S. (1949). The Monte Carlo Method. Journal of the American Statistical Association. 44 (247): $335-341$. doi:10.1080/01621459.1949.10483310.

Swain, J. (1997). Software Tools in High Energy Physics. In International Cosmic Ray Conference. 7: 357.

\section{Kaynaklar}

